\title{
TORRES, PIRAMIDES Y ESTRELLAS (SOBRE LAS IMAGENES DE LA ESTRUCTURA DE CLASES)
}

\author{
María Angeles Durán \\ CSIC
}

\begin{abstract}
RESUMEN
El objetivo de este artículo no es estudiar la desigualdad social en sí misma, sino las implicaciones teóricas y metodológicas de los instrumentos utilizados para medirla. De entre todas las manifestaciones de la desigualdad, se centra en sus aspectos más subjetivos: la autopercepción y la representación de la estructura.

El artículo se divide en tres partes. En la primera se plantean las cuestiones que afectan a la definición subjetiva de clase, distinguiendo entre el ser, el sentirse y el hacer. En la segunda se presentan, del modo más sistemático y abreviado posible, los resultados de casi cincuenta años (1950-1995) de investigación empírica en España sobre clases sociales. El objetivo de esta presentación crítica es mostrar las diferencias de enfoque y el efecto de la forma de aproximación de los investigadores sobre los resultados obtenidos. En la tercera parte se ofrecen los resultados inéditos, o escasamente divulgados todavía, de varias encuestas nacionales realizadas recientemente en el CSIC y en CIRES, en las que se ha concedido cierta relevancia al tema de la desigualdad social y sus manifestaciones actitudinales o autoperceptivas. A partir de estos resultados, y por comparación con los restantes, se analiza el imaginario colectivo español referido a la estructura social, lo que podría llamarse la nueva iconografía sociológica, y el papel jugado por los agentes sociales en la modelación de estas imágenes.
\end{abstract}




\section{ENTRE EL SER, EL SENTIRSE Y EL QUERER SER*}

En la investigación sobre estructura social, y especialmente sobre las clases sociales, se plantea constantemente el enfrentamiento conceptual entre el observado y sus observadores, entre las distintas perspectivas de los observadores y entre las varias concepciones de sí mismo y de la estructura social que tienen la mayoría de los sujetos. Estas concepciones se hacen explícitas de una u otra forma, dependiendo fundamentalmente de las necesidades o deseos que los sujetos perciben en los investigadores que buscan a través de ellos sus resultados.

Coxon ha señalado con claridad la multiplicidad de imágenes de clase que se suceden en un sujeto a lo largo del tiempo, y las que coexisten en un mismo momento y se utilizan para distintos propósitos. Estas diferentes imágenes se ofrecen a otros sujetos en la interacción social: entre ellos, a los sociólogos y los agentes sociales (el fisco, la Iglesia, los compañeros de trabajo, los vecinos, etc.) interesados en adscribirle un lugar ordinal respecto a otros.

La investigación empírica extensiva no suele entrar en matizaciones sobre el significado de las palabras con las que se pide a los observados que se identifiquen y, sin embargo, las respuestas son generalmente indéxicas, esto es, referidas a un contexto sobreentendido. Los cuestionarios emplean lenguajes «normalizados", pero sus palabras evocan promedios o ideas-síntesis cuyos componentes no están especificados en ningún sitio, y los entrevistados las toman y devuelven dándoles a su vez significados propios, relativamente homogéneos, pero sometidos también a idiosincrasias personales y a subculturas de grupo.

El lenguaje ofrece una riqueza de matices extraordinaria para referirse a la posición que el sujeto ocupa en la estructura. Las formas de relación más importantes son las de ser, estar, sentirse, querer ser y hacer como si fuera. Estas formas de relación son válidas tanto para el sujeto consigo mismo como para el sujeto respecto a otros sujetos o el conjunto de la sociedad, y para los sujetos externos (los observadores o investigadores) en relación al sujeto estudiado.

Ser, estar y haber son conceptos próximos, pero no iguales. "Haber», más impersonal y común que existir, suele emplearse para describir el conjunto de la estructura (preguntas del tipo «¿Cuántas clases sociales hay en España?»). El «ser» se emplea muy frecuentemente; y, sin embargo, gran parte de la población utiliza el «soy» con tan baja intensidad identificativa que correspondería mejor al «estar». Como sinónimos suelen usarse "pertenecer» o "formar parte», que tienen también una intensidad identificativa, una ontología, mucho más débil que el «ser»: además, ambos desplazan el foco de la conexión desde el

* Este artículo fue en su origen una ponencia presentada en el Grupo «Desigualdades Sociales» de la Federación Española de Sociología, en el IV Congreso (Granada, 1995). En cierto modo es continuación de otros trabajos previos, ya publicados, titulados «Necesidades sociales y nivel de satisfacción en la década de los noventa» (en P. Folguera, ed., Otras visiones de España, Fundación Pablo Iglesias, Madrid, 1995, pp. 213-277) y «Viejas y nuevas desigualdades: la dialéctica entre observadores y observados», Revista Internacional de Sociología, núms. 8-9, 1994, pp. 61-89. 
sujeto que se autopercibe hacia la clase de referencia, que es la que da sentido a la relación. Pero incluso cuando se emplea el más intenso de todos los vocablos posibles, el ser, éste viene atenuado por las partículas que le ligan a la clase: casi nunca y casi nadie dice "yo soy clase obrera" o "tú eres clase media" (del mismo modo que se dice "yo soy campesino» o "tú eres médico»), sino que se dice "yo soy de la clase obrera» o "tú eres de la clase media».

Junto al ser y al estar es esencial el «sentirse»: aunque no todos los sujetos tienen finura intelectiva como para distinguir entre matices, el sentimiento es un componente importante de la definición de clase. No puede ser fuerte una clase que no genera identificación, y no puede ser importante la identidad de clase de un individuo que se «sabe» perteneciente a ella pero su pertenencia no le provoca esa forma de reconocimiento afectivo que es el «sentirse». El sentimiento de clase no necesita emerger en condiciones de estabilidad, o, más aún, de estancamiento, cuando la inconsistencia es rara y las oportunidades de cambio personal y colectivo escasas. Sin embargo, en condiciones de cambio real o actitudinal, el sentimiento emerge como un elemento configurador poderoso, que se sobrepone al ser y al saberse más objetivo. Y no es sólo el viejo tema de la falsa conciencia o de los referentes positivos y negativos. El sujeto que se siente de una clase determinada en gran medida lo es, aunque contradiga indicadores materiales más objetivos como el nivel de renta o el nivel educativo.

Muy próximos al sentirse se sitúan el querer ser y el hacer como si fuera. El «querer ser» es a veces consciente, pero no siempre: explica a menudo mejor la conducta del sujeto que su clase de pertenencia, y es un estímulo, un incitante de grandes consecuencias. El estilo de vida, el énfasis en el estudio, el trabajo y el esfuerzo le están íntimamente ligados.

El problema de la relación entre el sujeto y "su» clase social es interesante, pero en una sociedad como la española actual, salvo muy contadas excepciones, no afecta a la identidad profunda. No hay duda de que cada sujeto individual existe, con independencia de cuál sea su posición en la estructura. Respecto a las clases sociales, el problema es distinto: ¿qué es lo que decide su existencia o inexistencia, su forma y sus internas relaciones? Aquí sí se plantea un problema ontológico, de ser o no ser: ¿qué es lo que diferencia una verdadera clase de una simple posición ordinal en una escala? ¿Quiénes tienen la capacidad real de construir las clases? ¿De dotarlas de existencia real o simplemente de reconocer lo que ya existía?

Sólo de modo metafórico puede hablarse de la construcción empírica de las clases, porque la empiria pertenece al dominio de las clasificaciones, de los conceptos o categorías; en definitiva, del conocer. Y las clases sociales - al menos así ha sido para gran parte de la investigación y de la acción social en los últimos cien años - tienen una existencia real, socialmente construida, a la que los investigadores no añaden realismo, sino solamente observación y análisis. O, dicho de otro modo, y a la inversa, si la investigación social construye realidad cuando la estudia, es tanto análisis como acción y rompe la supuesta frontera entre los reinos autónomos de la política y de la ciencia. 


\section{MEDIO SIGLO DE INVESTIGACIONES SOBRE DESIGUALDAD SOCIAL EN ESPANAA; LAS DIFERENCIAS DE ENFOQUE Y RESULTADOS}

\section{II.a) Clases y estratos: 1950-1981}

El último Informe Foessa (1994) inicia el análisis de la desigualdad social con la exposición de ocho estudios realizados entre 1950-1981 que, en opinión de los autores (Juarez y Renes), permiten una presentación panorámica y cronológica de la literatura española sobre estos temas (vid. tabla 1). Insisten en que «los estudios parten de presupuestos teóricos y metodológicos distintos, por lo que las cifras son poco comparables. Además de ello, se han escogido los datos que presentaban el mayor nivel de agregación posible, con vistas a no complicar en exceso estas reflexiones» (op. cit., p. 253).

Con independencia de la forma originaria de presentación de los datos, los estudios seleccionados se han agrupado en tres niveles, eclécticamente denominados estratos/clases, que son sólo ordinales; esto es, que no indican distancia social, sino posición relativa. A pesar del esfuerzo por lograr la convergencia en los «moldes» de la representación, el contenido varía considerablemente de unos estudios a otros, con oscilaciones que no pueden atribuirse tanto a la evolución estructural como a las diferencias de definición y medida. Así, por ejemplo, puede concluirse que la clase alta es muy pequeña según todos los

\section{TABLA 1}

Desigualdad social en España, 1950-1981

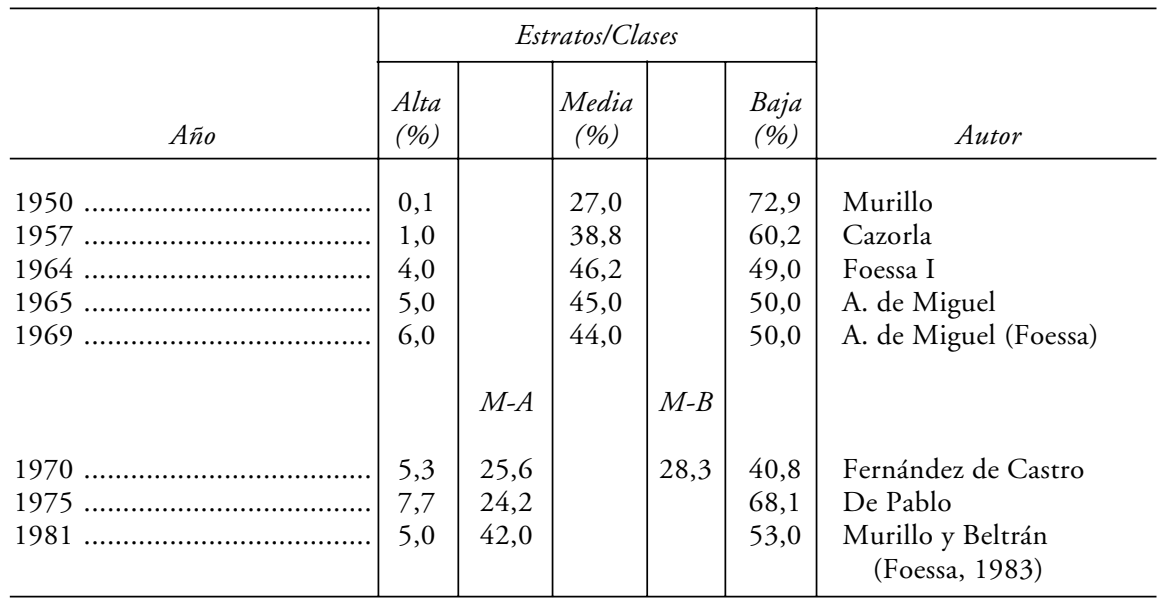

FUENTE: Reproducido del Informe Foessa 1994, p. 253. 
estudios; sin embargo, es setenta veces más grande en el estudio de De Pablo de 1975 (que la denomina "estrato dirigente») que en el estudio de Murillo de 1950. En cuanto a la clase baja, dos estudios relativamente próximos en el tiempo, como el de Fernández de Castro (1970) y el de De Pablo (1975), presentan estimaciones de volumen que también difieren entre sí en un 70 por 100 (27 por 100 en términos absolutos).

\section{II.b) La ocupación como criterio básico. \\ ¿Qué hacer con los dos tercios de adultos no ocupados?}

Para épocas más recientes, el Foessa 94 ha recogido otras fuentes: las estimaciones de Díaz-Salazar siguiendo la versión primitiva de Wright, el modelo de Goldhorpe y el llamado modelo de la Nueva Categoría Socioeconómica; todos ellos se reproducen en la tabla 2. El estrato más alto es cinco veces más voluminoso en unas estimaciones que en otras; el estrato intermedio, casi cuatro veces, y el estrato más bajo, casi doble. Juárez y Renes se decantan por una representación cuatripartita, con dos segmentos de clase media, basada en la propia encuesta Foessa 93. Y, lo que es más interesante, concluyen utilizando las series de la EPA porque "a la vista de los datos [se refieren a los estudios anteriormente citados] la validez de la clasificación según Condición Socioeconómica del INE es a grosso modo más que suficiente para representarnos medianamente bien la estructura de clases española... y la evolución seguida durante los últimos años" (op. cit., p. 257).

Aunque analicen la desigualdad social en España, los quince estudios de referencia se basan en la ocupación. Probablemente, la aportación más interesante a este tema (aparte de su muy desarrollado tratamiento de la pobreza y la inmigración) sea una consideración, apenas apuntada, sobre el hecho de que "los datos que resultan trascendentales para trascender la pura ocupación y construir una clase social, únicamente se han aplicado a aquellos entrevistados que se encontraban trabajando en el momento de realizar la encuesta, o de vacaciones $o$ baja temporal por enfermedad... Casi la única posibilidad de análisis que nos queda consiste en tratar de referirnos a la estructura de clases española a partir de las respuestas ofrecidas por el 39 por 100 de los entrevistados» (op. cit., p. 262).

Después de la constatación de que el 61 por 100 de los españoles mayores de edad no son clasificables en función de su ocupación, cabe preguntarse por qué se mantiene este criterio como el decisivo para servir de base a las representaciones de la desigualdad. Y, probablemente, concluir que ha llegado el momento de recabar mayor imaginación a los sociólogos para generar otros instrumentos de análisis. Es excesivo el peso concedido a representaciones de la desigualdad basadas en las escalas de ocupación, que han tenido mucha utilidad en las sociedades industriales del pleno empleo pero son dudosamente eficaces para la interpretación de las desigualdades en sociedades como la española de los años noventa. 
TABLA 2

Las representaciones de la desigualdad en España, Circa 1990

\begin{tabular}{|c|c|c|c|c|c|c|c|c|c|c|c|c|c|}
\hline $\begin{array}{c}\text { A } \\
\text { Diaz-Salazar, } \\
\text { sobre Wright }\end{array}$ & $\%$ & $\begin{array}{c}\text { B } \\
\text { González, } \\
\text { sobre Wright }\end{array}$ & $\%$ & $\begin{array}{c}\text { C } \\
\text { González, } \\
\text { sobre Goldhorpe }\end{array}$ & $\%$ & $\begin{array}{c}\text { D } \\
\text { Nueva categoría } \\
\text { socioeconómica, } \\
\text { según Carabaña }\end{array}$ & $\%$ & $\begin{array}{c}\text { E } \\
\text { Nueva categoria } \\
\text { socioeconómica, } \\
\text { según Juárez }\end{array}$ & $\%$ & $\begin{array}{c}F \\
\text { Condición } \\
\text { socioeconómica. } \\
\text { INE, EPA 4. }{ }^{\circ} \text { trim. } 1992\end{array}$ & $\%$ & $\begin{array}{c}G \\
\text { Foessa 94, } \\
\text { según encuesta } \\
\text { Foessa } 93\end{array}$ & $\%$ \\
\hline $\begin{array}{l}\text { I. Clase burguesa y capitalista } \\
\text { 1. Empr. agríc. con asal. } \\
\text { 2. Empr. no agríc. con asal. } \\
\text { 3. Director y Gerente } \\
\text { 4. Jefes Dept. y serv. }\end{array}$ & $\begin{array}{l}5,6 \\
0,3 \\
3,3 \\
1,0 \\
1,0\end{array}$ & $\begin{array}{l}\text { I. Propiet. med. prod. } \\
\text { 1. Empresa } \\
\text { 2. Peq. burg. }\end{array}$ & $\begin{array}{r}27,0 \\
3,2 \\
23,8\end{array}$ & $\begin{array}{l}\text { I. Clase de servicio } \\
\text { 1. Nivel alto } \\
\text { 2. Nivel bajo }\end{array}$ & $\begin{array}{r}20,8 \\
6,3 \\
14,5\end{array}$ & $\begin{array}{l}\text { I. Clases propiet. } \\
\text { 1. Empleados } \\
\text { 2. Autónomo expet. } \\
\text { 3. Autónomo cualif. } \\
\text { 4. Autónomo no cual. }\end{array}$ & $\begin{array}{r}28,1 \\
3,4 \\
2,8 \\
11,5 \\
10,4\end{array}$ & $\begin{array}{l}\text { I. Clase alta } \\
\text { 1. Empleados } \\
\text { 2. Direct. experto }\end{array}$ & $\begin{array}{l}5,9 \\
3,4 \\
2,5\end{array}$ & $\begin{array}{l}\text { I. Clase alta } \\
\text { 1. Empresa. agr. con asal. } \\
\text { 2. Empr. no agr. con asal. } \\
\text { 3. Dir. y jefes empresa }\end{array}$ & $\begin{array}{l}6,07 \\
0,36 \\
4,51 \\
1,20\end{array}$ & $\begin{array}{l}\text { I. Empleados y directivos } \\
\text { 1. Empresas con asalar. } \\
\text { 2. Direc. y gerent. }\end{array}$ & $\begin{array}{l}6,0 \\
3,9 \\
2,0\end{array}$ \\
\hline $\begin{array}{l}\text { II. Pequeña burguesía } \\
\text { 1. Prof. lib. cta. prof. } \\
\text { 2. Empr. sin asal. } \\
\text { 3. Empr. agríc. sin asal. } \\
\text { 4. Prof. y tec. por cta. ajena }\end{array}$ & $\begin{array}{r}29,8 \\
1,2 \\
11,8 \\
7,8 \\
9,0\end{array}$ & $\begin{array}{l}\text { II. Clase media } \\
\text { 1. Direc. experto } \\
\text { 2. Direc. no experto } \\
\text { 3. Supervisor experto } \\
\text { 4. Super. no experto } \\
\text { 5. Empleado experto }\end{array}$ & $\begin{array}{r}16,6 \\
2,5 \\
4,7 \\
1,7 \\
4,4 \\
4,0\end{array}$ & $\begin{array}{l}\text { II. Clases intermed. } \\
\text { 1. No manual alto } \\
\text { 2. No manual bajo } \\
\text { 3. Peq. empleado } \\
\text { 4. Autónomo } \\
\text { 5. Agricultor } \\
\text { 6. Superv. manual }\end{array}$ & $\begin{array}{r}45,9 \\
17,9 \\
3,9 \\
2,5 \\
11,5 \\
6,5 \\
3,6\end{array}$ & $\begin{array}{l}\text { II. Cuadro organ. } \\
\text { 1. Directivo experto } \\
\text { 2. Direct. no experto } \\
\text { 3. Supervis. experto } \\
\text { 4. Superv. no experto }\end{array}$ & $\begin{array}{r}13,5 \\
2,5 \\
1,2 \\
4,3 \\
5,5\end{array}$ & $\begin{array}{l}\text { II. Clase media } \\
\text { 1. Autón. experto } \\
\text { 2. Autón. cualif. } \\
\text { 3. Autón. no cual. } \\
\text { 4. Direc. no exp. } \\
\text { 5. Superv. exper. } \\
\text { 6. Suprv. no exp. } \\
\text { 7. Empl. experto } \\
\text { 8. Empl. semiexp. }\end{array}$ & $\begin{array}{r}47,3 \\
2,8 \\
11,5 \\
10,4 \\
1,2 \\
4,3 \\
5,5 \\
3,0 \\
7,6\end{array}$ & $\begin{array}{l}\text { II. Clase media } \\
\text { 1. Empr. sin asal. agric. } \\
\text { 2. Empr. sin asal. no agr. } \\
\text { 3. Profes. cuenta propia } \\
\text { 4. Profes. cuanta ajena } \\
\text { 5. Jefes Departamento } \\
\text { 6. Asal. admin. y comerc. }\end{array}$ & $\begin{array}{r}46,96 \\
5,85 \\
11,42 \\
1,40 \\
10,17 \\
0,95 \\
17,17\end{array}$ & $\begin{array}{l}\text { II. Vieja clase media } \\
\text { (rural y urbana) } \\
\text { 1. Profes. liber. } \\
\text { 2. Empr. sin asalar. } \\
\text { 3. Empr. agric. sin asal. } \\
\text { 4. Militares }\end{array}$ & $\begin{array}{r}21,8 \\
\\
2,2 \\
15,7 \\
3,2 \\
0,8\end{array}$ \\
\hline $\begin{array}{l}\text { III. Clase trabajadora } \\
\text { 1. Pers. adm., comer. y téc. } \\
\text { 2. Contramaestre y capataz } \\
\text { 3. Pers. serv. obr. y no obr. } \\
\text { 4. Obreros especializados } \\
\text { 5. Obreros sin especializar } \\
\text { 6. Obreros agrícolas }\end{array}$ & $\begin{array}{r}60,6 \\
15,7 \\
1,5 \\
10,5 \\
23,4 \\
5,8 \\
3,7\end{array}$ & $\begin{array}{l}\text { III. Clase trabajadora } \\
\text { 1. Trab. cualif. } \\
\text { 2. Proletario }\end{array}$ & $\begin{array}{l}55,7 \\
18,5 \\
37,2\end{array}$ & $\begin{array}{l}\text { III. Clase obrera } \\
\text { 1. Obrero cualif. } \\
\text { 2. Obrero no cual. } \\
\text { 3. Obrero agrario }\end{array}$ & $\begin{array}{r}33,4 \\
14,9 \\
15,6 \\
2,9\end{array}$ & $\begin{array}{l}\text { III. Empleados } \\
\text { 1. Empleado experto } \\
\text { 2. Empl. semiexperto } \\
\text { 3. Empl. cualific. } \\
\text { 4. Empl. no cualif. }\end{array}$ & $\begin{array}{r}58,9 \\
3,0 \\
7,6 \\
28,6 \\
19,2\end{array}$ & $\begin{array}{l}\text { III. Clase trabaj. } \\
\text { 1. Trab. cualif. } \\
\text { 2. Trab. no cualif. }\end{array}$ & $\begin{array}{l}47,8 \\
28,6 \\
19,2\end{array}$ & $\begin{array}{l}\text { III. Clase trabajadora } \\
\text { 1. Contram. y capat. } \\
\text { 2. Asalar. servicios } \\
\text { 3. Cooperativistas } \\
\text { 4. Trab. cualif. y espec. } \\
\text { 5. Obreros sin espec. } \\
\text { 6. Obreros agric. } \\
\text { 7. Militares } \\
\text { 8. No clasificables }\end{array}$ & $\begin{array}{r}44,07 \\
1,29 \\
11,12 \\
0,83 \\
22,98 \\
4,81 \\
3,04 \\
0,75 \\
2,14\end{array}$ & $\begin{array}{l}\text { III. Nuevas capas medias } \\
\text { de empleados } \\
\text { 1. Profes. y técn. asal. } \\
\text { 2. Administrativos } \\
\text { IV. Clase trabajadora } \\
\text { 1. Otro pers. servicios } \\
\text { 2. Obr. espec. } \\
\text { 3. Cooperativistas } \\
\text { 4. Obr. no espec. } \\
\text { 5. Peones agrarios }\end{array}$ & $\begin{array}{r} \\
\\
\\
35,9 \\
5,1 \\
16,7 \\
10,8 \\
1,5 \\
1,7\end{array}$ \\
\hline
\end{tabular}

FUENTE: Realizado por la autora sobre la reproducción en Foessa 1994, pp. 254-264. 
En el corto período entre 1991 y 1995, las dos encuestas CIRES sobre Desigualdades Sociales han reflejado la progresiva dismimución del tiempo vendido en el mercado de trabajo. Menos de la mitad de los entrevistados mayores de dieciocho años están trabajando; sólo un tercio está trabajando actualmente (39 por 100 en 1991) y sólo una cuarta parte de los adultos trabaja a tiempo completo (26 por 100 en 1995 , frente a 33 por 100 en 1991). La proporción de quienes buscan trabajo ha aumentado (13 por 100 frente a 9 por 100 en 1991), aunque se mantiene estable la de quienes buscan trabajo por primera vez.

Es más que dudoso que la estructura de clases derivada de la ocupación sirva como marco de referencia para interpretar la estructura global de la sociedad española. Los parados, especialmente los de larga duración, encajan muy mal en este esquema interpretativo; los jubilados, de modo creciente, no son jubilosos por su salario sin contrapartida de esfuerzo, sino trabajadores potenciales, en paro forzoso por despido administrativo; los estudiantes prolongan los años de estudio en muchos casos como un aparcamiento o cobijo, en tanto llaman a la puerta del mercado de trabajo; pero su nivel de estudios (esto es, las aspiraciones a que el título les da derecho) no coincide con el de su familia de origen. $Y$ en cuanto a las amas de casa a tiempo completo, al menos la mitad querrían trabajar y sienten que, por una u otra razón (la mitad porque están ya ocupadas en el cuidado de sus hijos y esposo, y no les queda tiempo excedente), se les impide el acceso al coto cerrado del empleo retribuido.

Los importantes esfuerzos invertidos en analizar los grados de asociación entre variables han dado hasta ahora poco juego real. Sin duda, algunos conceptos (por ejemplo, la "categoría socioeconómica» que propugna J. J. González) dan una $\mathrm{R}$ más alta que en otras variables en relación con los ingresos laborales, pero eso no significa necesariamente que describan mejor la estructura de clases: puede muy bien interpretarse como proximidad entre esos conceptos, y descuido de otros conceptos fundamentales, como la autoimagen, con los que la correlación es más baja.

\section{II.c) Escalas relacionales y mixtas: los problemas de convertibilidad}

La tabla 3 presenta los resultados de varias estimaciones realizadas entre 1990 y 1994. Las escalas utilizadas por Durán, CIRES 93/94 y Foessa 94 (reagrupada) son puramente relacionales. En cambio, la clasificación de Tezanos (reagrupación de respuestas, según cita de Juárez) y la originaria de Foessa 94 son en parte relacionales (para los niveles alto y medio) y en parte responden a criterios y denominaciones no directamente relacionales («trabajadora»y «obrera», según Tezanos; «obrera» y "pobre», según la escala originaria de Foessa 94). En la clasificación de Tezanos, tanto la categoría «trabajadora» como «obrera» están situadas por debajo de la media y por encima de la baja. 


\section{TABLA 3}

Autoimagen de clase en España, Circa 1990, varias encuestas

\begin{tabular}{|c|c|c|c|c|c|c|c|c|c|}
\hline$A$ & & \multicolumn{2}{|l|}{$B$} & \multicolumn{2}{|l|}{ C } & \multicolumn{2}{|l|}{$D$} & \multicolumn{2}{|c|}{$E$} \\
\hline \multicolumn{2}{|l|}{ END 1990} & \multirow{2}{*}{\multicolumn{2}{|c|}{ (Tezanos) }} & \multirow{2}{*}{\multicolumn{2}{|c|}{ CIRES 93/94 }} & \multicolumn{2}{|l|}{ Foessa 94} & \multicolumn{2}{|c|}{ Foessa 94} \\
\hline (Durán) & & & & & & (original & & $\begin{array}{l}\text { (rea } \\
\text { (Juár }\end{array}$ & $\begin{array}{l}\text { ass) } \\
\text { nes) }\end{array}$ \\
\hline Alta & * & Alta & 3,0 & Alta & * & Alta & 0,2 & & \\
\hline Media-alta & 7 & Media & 49,4 & Media-alta & 3 & Media-alta & 5,3 & & \\
\hline Media-media & 61 & Trabajadora & 14,7 & Media-media & 52 & Media & 49,3 & & \\
\hline Media-baja & 24 & Obrera & 5,7 & Media-baja & 32 & Media-baja & 19,0 & & \\
\hline Baja & 8 & Baja & 13,9 & $\begin{array}{l}\text { Baja } \\
\text { S.R. }\end{array}$ & 10 & $\begin{array}{l}\text { Obrera } \\
\text { Pobre }\end{array}$ & $\begin{array}{r}24,1 \\
2,1\end{array}$ & Baja & 45,2 \\
\hline
\end{tabular}

FUENTES:

A: Encuesta de Nuevas Demandas Sociales (dirigida por M. A. Durán, 1990).

B: Encuesta dirigida por Tezanos.

C: Series periódicas de CIRES 1993-1994, con elaboración posterior de M. A. Durán.

D: Encuesta Foessa 1993 (dirigida por López Pintor y Juárez).

E: Encuesta Foessa 1993, reelaborada por Juárez y Reyes.

Todas las escalas son difícilmente comparables con otras; no sólo tienen diferente número de intervalos, sino que responden a definiciones e intereses diferentes. Desde la perspectiva de las posibilidades de movilización política o de generación de autoconciencia de clase, las clasificaciones puramente relacionales tienen menos interés que otras categorías con más contenido ideológico, como «trabajador» u "obrero». Aunque eso impida que el colectivo de los obreros (trabajadores manuales por cuenta ajena) ocupe en el conjunto de la sociedad española una posición inferior a la de los empleados y que la expectativa de las familias obreras sea que sus hijos dejen de serlo para convertirse en empleados y cuadros medios, la denominación obrera conserva un prestigio asociado a los movimientos sociales históricos, especialmente a los movimientos sindicales. Las implicaciones semánticas de los términos «trabajador» y «obrero» son muy fuertes. De ahí que partidos políticos como el PSOE las mantengan en sus siglas, igual que los sindicatos UGT y CC.OO., aunque gran parte de sus dirigentes, votantes y afiliados respondan ocupacionalmente a un perfil de empleados, funcionarios "laborales» de las grandes empresas públicas, rentistas jubilados y otros ciudadanos ajenos al mercado de trabajo. 
La escala reagrupada de Foessa 94 (E) ejemplifica muy bien los problemas metodológicos de las escalas de representación. La escala originaria (D) tenía seis niveles, que se reducen a tres en la reagrupada (E). Si los sujetos entrevistados se autoperciben como miembros de la clase media (media-alta, mediamedia y media-baja) en una proporción del 73,6 por 100 , ¿ tiene sentido forzar la representación hacia un esquema tripartito, alterando la autoidentificación de los sujetos para repartir el amplio núcleo central entre la clase alta (a la que se añade la media-alta) y la baja (a la que se añade la media-baja)? Es un caso muy evidente en que el experto corrige las palabras del sujeto observado.

Sería más fácil hacer esta corrección en escalas que pretenden medir la distribución «real» de la población según variables objetivas (por ejemplo, si se contrastase con una mejor información sobre patrimonios), pero no parece que, tras este ejercicio de trueque, del que en mayor o menor medida participan todos los estudios sobre desigualdad, pueda concluirse que la autoimagen o percepción subjetiva de clase media es sólo la correspondiente al nivel central de esta categoría. Al menos en autopercepción manifestada, la sociedad española es una sociedad de clases medias, porque así se manifiestan tanto los niveles superiores como los inferiores a ese núcleo central de la clase media-media.

Un tema distinto, y muy interesante desde el punto de vista teórico y metodológico, es el de la pedagogía del aprendizaje no explícito de las imágenes de clase; qué medios las conforman, y con qué eficiencia o capacidad de obligar. Por ejemplo, dentro del lenguaje relativamente neutral del Informe Foessa 94 se describe a los componentes de la clase alta (escala reagrupada) como "la suma de la clase media-alta y el pequeño grupo que no tienen empacho alguno en afirmarse como de "clase alta"». El "empacho" en "afirmarse» de clase alta se da por supuesto, asumiendo que es una posición que acarrea algún tipo de dificultad, una especie de vergüenza o temor por disfrutar de excesivos privilegios, que fuerza a los entrevistados a no afirmarse en ella, por lo menos voluntariamente.

En una sociedad de clases y en un contexto democrático, la clase alta no puede hacerse muy evidente, o peligraría. De ahí la privacidad de sus manifestaciones, el carácter relativamente recóndito de su ubicación material. Las residencias más lujosas no se exhiben a la contemplación pública en los lugares de mayor accesibilidad, como las antiguas plazas (daría «empacho» esta proclamación), sino que se protegen de la visión ajena por recintos cerrados, por clubes y centros de acceso selectivo. La propiedad tampoco es directa, inmediata, aunque pueda serlo su control y disfrute: la mayor parte se interpone a través de sociedades anónimas en que el rostro de los dueños es invisible. Y las encuestas de ocupación asignan el mismo lugar al asesor sin acceso al patrimonio que a quienes pueden movilizar, propios o ajenos, recursos equivalentes a la renta anual de una comunidad pequeña.

Algunos "creadores de imagen" son auténticos manuales de la transición (en el "querer ser» y en el "hacer como si fuera») entre la clase media y la alta: entre ellos, los «clubes selectivos» de las tarjetas-oro, los vips y similares, que 
disponen de publicaciones propias para enseñar la "gama alta» del modo de vida y de consumo.

\section{II.d) La ubicación social de los pobres}

En el extremo opuesto, el mismo tipo de penalización psicológica se aplica a los autorreconocidos como pobres, por el estigma de incapacidad, fracaso y rechazo externo que — salvo en ocasiones de militancia ideológica-conlleva.

La pobreza es un desiderátum (un voto para siempre) de algunas categorías muy específicas de personas, que hacen de ella una condición de vida, un instrumento para alcanzar otros objetivos. Forma parte de los tres votos principales (castidad, pobreza y obediencia) en numerosas órdenes religiosas y también, aunque con menos compromiso, en algunos tipos de asociaciones civiles. La distinción entre pobreza individual y pobreza institucional es imprescindible en el análisis de la desigualdad, porque con frecuencia no coinciden. En casos extremos la carencia de propiedades personales se superpone al disfrute y control de fantásticos lujos tanto rituales como materiales. ¿A qué clase social pertenecen los "pobres voluntarios»? ¿En qué medida son «uno de ellos», o son los otros, los pobres sin elección, el «ellos para mí», la base de su poder y fortuna? ¿Qué tipo de simbiosis social se produce en estos casos extremos de disparidad entre el «ser», el «sentir», el «hacer» y el «querer ser»?

Como ya señalábamos, el autorreconocimiento como pobre tiene connotaciones de fracaso y rechazo para gran parte de la población, que evade este marcaje negativo de muchas maneras. Entre otras, disminuyendo los contactos con personas pertenecientes a otros estratos que harían más evidente la distancia, y creando un ámbito de normalidad cotidiana respecto al cual ocupan posiciones intermedias. En este sentido, los marginales (drogadictos especialmente), los inmigrantes (especialmente los de color) y los "pobres internacionales» (los de otros países, conocidos a través de la TV y otros medios de comunicación) juegan un papel de referencia importante, y refuerzan el sentimiento de abundancia relativa en los estratos más bajos de la población española. En otras palabras, les empujan hacia una identidad de clase media.

Los ideólogos sociales (políticos, religiosos) asumen la tarea de construir la realidad social al mismo tiempo que la analizan, o viceversa. Para cambiarla, a veces, y otras solamente para permeabilizarla en usos e ideas: es la dotación de autoimagen, el despertar de la conciencia social o pertenencia de clases. Pero ésta es una tarea complicada, en la que resulta más fácil acentuar los rasgos no equitativos del conjunto, de la estructura, que lograr de los sujetos individuales su autoposicionamiento en los estratos inferiores.

Por ejemplo, según la encuesta Foessa 93, sólo la mitad de quienes «son» pobres según su condición socioeconómica se autorreconocen como pobres. Pero, en contraste con esta presión hacia el centro, el 5 por 100 de los que se autodefinen como clase media-alta corresponde "objetivamente» al nivel infe- 
rior al umbral de la pobreza, y lo mismo sucede con un 10 por 100 de la clase media-media, un 22 por 100 de la media-baja y un 24 por 100 de la obrera. Dicho con otras palabras, sólo el 7 por 100 de quienes son definidos externamente como pobres se «sienten» pobres; y más de la mitad (55 por 100) de los que son definidos como pobres se sienten dos o más estratos más altos de lo que les correspondería si coincidiese la definición externa y la autopercepción (tabla 4).

\section{TABLA 4}

Pobreza subjetiva y definición externa del umbral de pobreza según Foessa 1994

\begin{tabular}{|c|c|c|c|c|}
\hline \multirow[b]{3}{*}{ 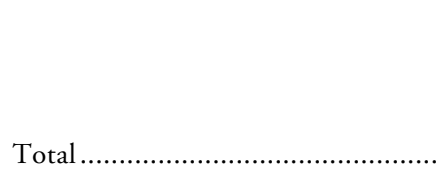 } & \multicolumn{2}{|c|}{ Bajo el umbral de pobreza } & \multicolumn{2}{|c|}{ Sobre el umbral de pobreza } \\
\hline & $A$ & $B$ & $A$ & $B$ \\
\hline & 16,44 & 100,00 & 83,56 & 100,00 \\
\hline Alta & - & - & 100,00 & 0,10 \\
\hline 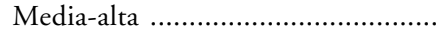 & 4,87 & 1,40 & 95,13 & 5,44 \\
\hline 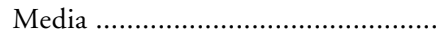 & 9,57 & 27,37 & 90,43 & 50,98 \\
\hline 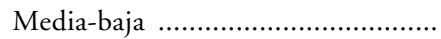 & 21,61 & 25,77 & 78,39 & 18,38 \\
\hline 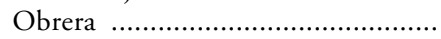 & 24,29 & 38,76 & 75,71 & 23,74 \\
\hline 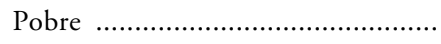 & 49,91 & 6,69 & 50,09 & 1,32 \\
\hline TOTAL POBLACIÓN $(\mathrm{N})$ & \multicolumn{2}{|c|}{1.001} & \multicolumn{2}{|c|}{5.088} \\
\hline
\end{tabular}

FUENTE: Informe Foessa 1994, p. 302, reelaboración por la autora.

NotA DE LA AUTORA: La columna A presenta el porcentaje que se siente pobre en cada clase social objetiva. La columna B presenta la distribución entre clases objetivas de los que se sienten pobres.

\section{LAS REPRESENTACIONES DE LA ESTRUCTURA SOCIAL: LA NUEVA ICONOGRAFIA DE LAS CLASES}

\section{III.a) Autoimagen y adscripción externa}

En la encuesta de Nuevas Demandas de 1990* (en adelante, END), sólo 4 por 100 de los entrevistados dejaron de responder a la pregunta sobre la clase

* Esta encuesta formó parte del proyecto de investigación «Las bases sociales de la economía española», financiado por la Comisión Interministerial de Investigación Científica y Técnica (1989-1991) y dirigido por M. A. Durán. Consta de una encuesta nacional (2.500 entrevistas) y una encuesta regional, en la Comunidad Autónoma de Aragón (1.200 entrevistas). 
social a que pertenecían. Comparado con las escalas de ingresos, en las que además de la evidencia de ocultación suele producirse una cuarta parte de negativas a responder, este nivel de respuesta es muy elevado. La alta propensión a la respuesta se debe principalmente a tres factores:

1. En los últimos veinticinco años, los medios de comunicación y los documentos administrativos han generalizado el uso de escalas de autoposicionamiento y cuestionarios de todo tipo.

2. A diferencia de las preguntas sobre patrimonio o ingresos, de esta cuestión no se deriva ningún tipo de riesgo fiscal, directo o indirecto.

3. Por tratarse de una simple opinión, los entrevistados no perciben en ella tanta exigencia de precisión o veracidad como en las preguntas sobre hechos.

El primer factor pone de relieve la interacción entre los modos de investigación y la realidad social investigada. La acción de los investigadores ha dotado de una realidad social que antes no tenían - aunque existiesen- a los temas investigados por ellos en el proceso de producción científica.

El segundo factor nos conduce a otro núcleo de problemas básicos en la investigación en ciencias sociales: el riesgo que asumen los sujetos entrevistados cuando se someten a la observación y el reconocimiento de sus diferencias ante los investigadores (la percepción, comprensión, ocultación y manifestación de los fenómenos sociales). En definitiva, el problema de la realidad social fuera de la mente de los individuos que la componen y la capacidad de propios y ajenos para reconocerla y reconocerse.

Finalmente, el tercer factor deriva de los dos primeros, pero plantea un problema concreto y aplicado a los investigadores: ¿vale la pena trabajar con indicadores tan imprecisos y tan poco susceptibles de contrastación por otros medios? La respuesta, obviamente, es positiva, a pesar de las objeciones de quienes piensan que lo que sucede al nivel social y psicológico (las actitudes, las representaciones, las identidades, etc.) no tiene una entidad comparable - por poner un ejemplo- a los títulos de propiedad, y sólo confieren la categoría de reales a estos últimos.

En la END se omitió deliberadamente cualquier referencia a términos connotados con la sociedad estamental (como aristocracia), a la teoría de las élites, al conflictivismo (como "proletariado», "explotados» "trabajadores», etcétera) o incluso con el análisis de problemas sociales (como "pobre» o "marginal»). El estudio pretendía conocer la asociación entre autoimagen de clase y la imagen que el entrevistado produce externamente. Para ello se solicitó de los entrevistados que se autoposicionaran en una escala relacional de cinco intervalos y se pidió a los entrevistadores que, al término de la entrevista domiciliaria (en la que también se solicitaba información sobre ocupación, nivel de ingresos, nivel de estudios, composición del hogar, estado civil, etc.), situasen al entrevistado en una escala ordinal de once intervalos. 
La escala de autoposicionamiento de la END sólo empleaba palabras relacionales: alta, media-alta, media-media, media-baja, baja. No fue ajeno a esta decisión que, según el Informe sociológico sobre el cambio social en España, 1975-83*, a la pregunta sobre cuántas clases sociales había en España, la respuesta más frecuente fuese «tres» (31 por 100), seguida de «no sé» (29 por 100) y una gran dispersión entre dos y siete clases, con sólo un 3 por 100 que dijo "ninguna» y un porcentaje insignificante de "sólo una». Los datos de este Informe Foessa 83 provenían de una encuesta recogida en 1981 y venían a corroborar lo que los investigadores sociales habían detectado también en otros sondeos y observaciones directas de la sociedad española: el decaimiento de la tensión ideológica que impulsó la investigación social en la década del 65-75 hacia temas e interpretaciones conflictivistas, en las que el concepto de "clase» desempeñó un papel importante, vinculado al marxismo y a las orientaciones políticas de izquierdas.

Si sólo cuatro de cada cien entrevistados dejaron de contestar a la escala de autoimagen en la END, los entrevistadores dieron una proporción más alta en la escala de percepción externa: para ellos, no se trataba de una simple opinión $y$, ante la falta de información y la duda, dejaron de emitir su respuesta con una frecuencia doble a la de los propios entrevistados. Sin embargo, no tuvieron ninguna dificultad en utilizar todos los intervalos disponibles en su escala ampliada.

La conversión de una escala de once puntos en otra de cinco no puede hacerse automáticamente y fuerza a que uno de los intervalos contenga tres puntos en lugar de dos, como los restantes. Para analizar la relación entre autoimagen de clase y percepción externa se realizaron dos tipos de conversión de la escala de once puntos a la de cinco: en la que llamamos escala simétrica se agrupan tres intervalos en el punto medio de la escala, y en la otra escala, o escala desplazada, se agrupan los tres más bajos. La primera conversión es más correcta desde un punto de vista lógico, porque son posiciones centrales, pero la segunda permite localizar mayor número de sujetos en el intervalo inferior, acercando así los resultados a otras distribuciones, como la de ingresos o nivel de estudios.

En la tabla 5 se expresa la coincidencia y la discoincidencia entre la imagen autopercibida y la externa, con una conversión de escala simétrica. Como puede verse, hay un predominio total de las identificaciones con la clase media; sólo 3 por 100 quedan fuera en la imagen externa y 9 por 100 en la autoimagen. Dentro de la amplia cobertura de la clase media, la identificación de clase media-alta es mucho menos frecuente que la de media-baja (24 por 100 en autoimagen, 17 por 100 en la escala simétrica de evaluación externa y 32 por 100 en la escala desplazada).

* Fundación Foessa, Informe sociológico sobre el cambio social en España, 1975-1983, Madrid, Euramérica, 1983. Especialmente, F. Murillo y M. Beltrán, Estructura Social y Desigualdad en España, con datos de encuesta realizada por el CIS en junio 1981. 


\section{TABLA 5}

Coincidencia y distorsión en las percepciones de clase

\begin{tabular}{|c|c|c|c|c|c|c|}
\hline \multirow[b]{2}{*}{ Autoimagen } & \multicolumn{6}{|c|}{ Imagen externa (escala simétrica) } \\
\hline & $\begin{array}{l}\text { Alta } \\
10-9\end{array}$ & $\begin{array}{c}\text { Med.-alta } \\
8-7\end{array}$ & $\begin{array}{c}\text { Med.-med. } \\
6-5-4\end{array}$ & $\begin{array}{c}\text { Med.-baja } \\
3-2\end{array}$ & $\begin{array}{c}\text { Baja } \\
1-0\end{array}$ & $\begin{array}{l}\text { Total } \\
\text { vertc. }\end{array}$ \\
\hline Alta & 6 & * & * & * & - & * \\
\hline Media-alta ............................. & 55 & 31 & 3 & 1 & 4 & 7 \\
\hline Media-media ......................... & 35 & 59 & 71 & 31 & 25 & 61 \\
\hline Media-baja ….......................... & 6 & 8 & 22 & 41 & 13 & 24 \\
\hline \multirow{2}{*}{ 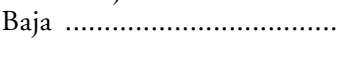 } & - & 2 & 3 & 27 & 58 & 8 \\
\hline & 100 & 100 & 100 & 100 & 100 & 100 \\
\hline TOTAL HORIZ. $(\%)$........... & 1 & 13 & 66 & 17 & 2 & 100 \\
\hline
\end{tabular}

Fuente: DURÁn et al., Las bases sociales de la economía española (Encuesta sobre Nuevas Demandas, Nacional, 2.490 entrevistas, 1990).

Base: Excluidos NS/NC $=2.217$.

Coincidentes en ambas imágenes $=60$ por 100

$\mathrm{NS} / \mathrm{NC}=4,2$ por 100 de autoimagen, 7,4 por 100 de imagen externa

En la escala desplazada, la distribución no varía en la clase alta y media-alta; la mediamedia es 49 por 100; media-baja, 32 por 100; baja, 9 por 100 .

Sólo algo más de la mitad de los sujetos (60 por 100) coinciden en su autoimagen de clase y en la que les atribuye externamente el entrevistador. Estos suelen atribuirles una posición más alta de la que se autoadscriben. Si en lugar de la escala simétrica usamos una conversión con la escala desplazada, agrupando los tres primeros puntos como equivalentes a clase baja, las coincidencias son aún menores ( 55 por 100). Tanto en la escala de autoimagen como en la externa, los discoincidentes difieren en la mayoría de los casos solamente en un intervalo, pero un 12 por 100 difiere en dos o más intervalos.

La disparidad entre ambas identificaciones es un dato digno de tenerse en cuenta, porque muestra la fragilidad de las estimaciones: pequeños detalles técnicos pueden producir grandes modificaciones en los resultados. Pero esta fragilidad no es más grave, sino solamente más consciente, en este tipo de estudios que en otros. De hecho, las grandes magnitudes que sirven a la planificación social y económica (por ejemplo, cifras de paro, estimaciones de producción, declaraciones de ingresos, datos de morbilidad, inmigración, etc.) sufrirían oscilaciones y desacuerdos parecidos si se sometieran a contrastaciones similares a las que aquí hemos puesto de relieve voluntariamente. 


\section{III.b) La individualización del voto y la familización de la clase}

No puede forzarse la tensión entre el modo político de expresión de las clases (que puede resumirse en la declaración, absolutamente individualista, de que cada ciudadano mayor de dieciocho años es un voto) y el modo afectivo/espacial al que dan soporte los hogares. Las familias son consideradas, de modo casi unánime, las unidades de clase elementales: pero en esta visión familista hay tanto de utopismo idealista y conservador como próximo al conflictivismo y materialismo es el análisis de la desigualdad social a través de la teoría de las clases sociales. La afirmación de Engels de que dentro de la familia se producen relaciones de explotación en las que corresponde a la mujer el papel de explotada ha sido casi borrada del posterior desarrollo de la teoría marxista, centrada en "construir» analítica y socialmente una estructura en la que los conflictos internos eran considerados (según autor y momento) irrelevancias o traiciones. Esta posición (desde la izquierda) ha coincidido sustancialmente con el mensaje de indisolubilidad y valores familistas (desde la derecha) que ha convertido el conflicto intrafamiliar en un pecado de desobediencia a los padres (como representación de la autoridad en el nivel más próximo) o de desobediencia al esposo y falta de respeto entre los cónyuges. El discurso de la cohesión familiar es, sin duda, un discurso dominante, arropado por coberturas ideológicas de muy distinto signo. Sin negar las sólidas bases afectivas de la familia, la investigación sobre desigualdades sociales tendría que revisar estos supuestos de identidad y aconflictivismo, que son mucho más profundos y difíciles de cuantificar que los análisis relativamente epidérmicos de ocupaciones.

Aunque para la mayoría de la población española actual son más relevantes las rentas salariales que los rendimientos del patrimonio, las familias siguen siendo unidades económicas fundamentales. El individualismo es muy fuerte como ideología política (una persona, un voto), pero la mayoría de la población (niños, jubilados, mujeres, estudiantes, enfermos, parados) no tiene ingresos propios suficientes para pagar individualmente los bienes y servicios que consume y en esta situación se encuentran también muchos de los que disponen de un salario.

En la Encuesta de Nuevas Demandas de 1990 (a mayores de dieciocho años), un tercio de los entrevistados dijo no tener ingresos propios, y un 15 por 100 no respondió o dijo desconocer su cuantía. Pero lo más relevante a efectos de imagen de clase es que estos entrevistados no reflejaron una autoimagen ni una imagen externa de clase distinta, como conjunto, a los que sí respondieron. Ello corrobora la idea de que la imagen de clase no sólo la generan los ingresos propios en el momento presente, sino el recuerdo de los que se tuvieron en otras épocas (jubilados), los que se espera llegar a tener (estudiantes) o los que obtienen otros familiares (cónyuges, hijos).

En todos los niveles de ingresos, la imagen de clase más frecuente es la media-media. Entre quienes dicen tener ingresos propios inferiores a cincuenta 
mil pesetas mensuales (en los que abundan los becarios, jubilados, rentistas, trabajadores a tiempo parcial, etc.), el 64 por 100 manifiesta tener otras fuentes de ingresos en el hogar. Esta proporción desciende paulatinamente hasta un 33 por 100 entre quienes ganan de cien a doscientas mil pesetas.

En conjunto, las mujeres tienen menos años de escolarización, hay menos mujeres que tengan ingresos propios y, cuando los tienen, es menor su nivel de ingresos: y aunque son mayoritariamente amas de casa, su autoimagen de clase es casi idéntica a la de los varones. En la escala de evaluación externa resultan evaluadas más altas que en su autoimagen. Esta evaluación externa contradice todos los datos objetivos sobre la feminización de la pobreza, pero no es sorprendente: las mujeres han aprendido tradicionalmente una «cultura de la supervivencia» que les permite sobrevivir en situaciones de carencia de recursos monetarios en que no podría desenvolverse la mayoría de los varones.

Si se controla por edad la autoimagen de clase, el resultado es un alza constante a favor de los más jóvenes, a partir de los veinticinco años. Aplicando una puntuación de uno a cinco puntos a los intervalos (uno el mínimo y cinco el máximo), los menores de veinticinco años obtienen una media de 2,9 puntos, que equivale al borde superior de la clase media-baja. La mayoría de estos jóvenes todavía no se ha incorporado plenamente al mercado de trabajo ni ha constituido su propia familia. En el grupo de edad siguiente (de veinticinco a treinta y cuatro años), ambas condiciones se dan ya y obtienen la máxima puntuación media de toda la población (3,6 puntos). A partir de esta edad la autoimagen de clase inicia un declive ininterrumpido $(3,1,3,0,2,9$ y 2,7$)$, terminando en 2,5 en los mayores de setenta y cinco años. Esta ventaja de los jóvenes refleja la huella de etapas anteriores del sistema educativo, además del aumento de responsabilidades familiares, la disminución de las expectativas de éxito, la salida por jubilación del mercado de trabajo y las dificultades de la vejez.

A pesar de esta patente familización de la clase, que Díaz-Salazar ha destacado especialmente a propósito de la clase obrera y que también ha sido destacada en estudios sobre la clase alta (las "familias" poderosas) o sobre el capital simbólico y de relaciones sociales de la clase media, es dudoso que la familia, en condiciones de creciente individualización, pueda seguirse usando acríticamente como unidad de identificación social. Engels localizó en el seno de la familia las relaciones de explotación, y no sólo en su exterior.

Cada vez es más frecuente e individualizada la relación de los que componen el hogar con el mercado de trabajo, y más desigual entre sí: ¿hereda automáticamente el joven parado el status de su padre bien establecido? ¿Puede asignarse la misma posición a las familias en que, por trabajar dos o tres personas, duplican los ingresos medios de su nivel profesional? ¿Pertenece a la clase de su esposo, o viceversa, la administrativa a tiempo parcial si su esposo es empresario? ¿Mantiene la posición en caso de viudez o de divorcio? Demasiados interrogantes para no pensar que es necesario un cambio en el modo de análisis. Más que porque piense que le corresponde el punto central de la pirá- 
mide o la escala, la población se siente clase media porque vive cada día este promedio de situaciones múltiples y cambiantes o lo vive delegadamente a través del círculo íntimo de allegados.

De todos modos, la autoimagen de clase más frecuente en todos los grupos de edad, igual que en todos los niveles de escolarización, es la de clase mediamedia. Para ello cuenta con la ayuda inestimable de un gran constructor imaginario de clases medias, que es el mercado. Los productos masivos u ofertados a través de los medios de comunicación necesitan receptores homogéneos para sus mensajes, y la creación del "ciudadano medio» es una exigencia y un logro del sistema publicitario. No todos los productos pueden ser comprados por todos los consumidores potenciales, pero el fin de cada spot y cada cartel es convencer a quien lo mira o lo oye que, ante ese producto particular, la relación de intercambio y posesión es posible. La identificación funciona con éxito, masivamente. A tenor de los resultados de todas las encuestas, parece como si la sociedad española, por encima de otras desigualdades persistentes, hubiera creado una nueva imagen de sí misma, como sociedad mesocrática, a la que se aferra y en la que quiere reconocerse.

\section{III.c) La aspiración al éxito como disolvente de la estructura de clases}

En CIRES se han realizado dos encuestas específicas sobre desigualdades sociales, en 1991 y 1995. Más de la mitad de la población cree que existen grandes desigualdades, y la opinión sobre si han aumentado o disminuido en los últimos años o se mantienen estables está bastante repartida (39 por 100 cree que ha aumentado, 31 por 100 sigue igual, 25 por 100 ha disminuido).

A diferencia de los estudios sobre clases sociales, en estas dos encuestas el objetivo no es tanto la ocupación cuanto los otros componentes de la posición relacionados con el poder, el prestigio y las probabilidades de acceso a mejores recompensas sociales. Es difícil establecer el límite entre los medios y los fines; por ejemplo, la educación y los ingresos: ¿son objetivos por sí mismos o sólo medios instrumentales? Si se tratase de reconvertir estos datos en un análisis de clases sociales: ¿qué significado tiene que la población considere que hay igualdad de oportunidades en educación o acceso al sistema sanitario (casi la mitad lo cree así) pero no tanto en la Justicia y menos aún en el acceso al empleo o a la mejora de ingresos (menos del 15 por 100 cree que hay igual$\mathrm{dad})$ ?

El concepto de éxito tampoco encaja con el de clases sociales, porque el primero es fundamentalmente individual y el segundo colectivo; pero los éxitos individuales o familiares masivamente conseguidos, percibidos como tales, sin duda afectan a las autoimágenes, a las imágenes de conjunto y a los sentimientos provocados por la posición de clase. Para el analista, tanto teórico como empírico, resulta sugerente la facilidad con que los entrevistados responden sobre sí mismos en categorías de éxito o en categorías de clase, dependien- 
do solamente de la aproximación utilizada por los observadores. El éxito podría interpretarse - al menos hasta cierto punto- como la capacidad de desclasarse hacia arriba, por cualquiera de las vías posibles, desde el matrimonio hasta los estudios o la actividad política. Pero también hay otros componentes del éxito menos relacionados con la movilidad ascendente, que hacen referencia implícita al afecto y reconocimiento sociales.

Según las encuestas CIRES citadas, el factor más importante para lograr éxito es tener estudios (191 puntos como promedio en una escala de 200), seguido de tener buenas relaciones, ambición, inteligencia y trabajar mucho (más de 175 puntos en la escala): éstas son en buena parte cualidades individuales, que pueden presentarse o estar ausentes en cualquier estrato o peldaño de las clases sociales o la pirámide social. Otros factores algo más ligados a componentes estructurales (como ser de familia rica, tener padres con estudios o poseer influencias políticas) también son señalados como factores relevantes (más de 135 puntos en la escala). Con todo, lo más sugerente para la comparación entre la aproximación individualista y la colectiva es que los factores más indelebles, los de adscripción (raza, sexo, región de procedencia), no se señalan por los entrevistados como importantes en estas encuestas. No parece que esta falta de señalamiento se deba a desconocer las desigualdades de renta o de posibilidades de acceso al empleo o al poder de los individuos nacidos en las regiones ricas y pobres, o varones y mujeres (más de una cuarta parte señala las especiales dificultades de las mujeres en relación a los empleos), o blancos y negros: más bien refleja la idea de que existen posibilidades de éxito ad hoc, esto es, que el éxito no es tanto, o no sólo, una competición universal de todos contra todos, sino que mide el ajuste entre las aspiraciones y el punto de partida, más que el punto de meta al que efectivamente se llega.

La educación aparece como objetivo y como instrumento en las imágenes de la población: en tanto que instrumento para reducir desigualdades en España, es la más citada (50 por 100); sin embargo, los instrumentos colectivos de confrontación (manifestaciones, protestas, etc.) sólo los cita el 10 por 100 de los entrevistados. Con ello se refleja la distancia, al menos en el plano de lo que se quiere decir, pero muy probablemente también en el de lo que se siente, entre la mayoría desorganizada y los movimientos militantes (especialmente sindicales y políticos) que usan de estos medios de presión. También el discurso sobre «lo que hay» es radicalmente distinto, pues mientras el discurso de los movimientos sociales es en gran parte el esfuerzo por explicitar y analizar el conflicto, en las encuestas generales de opinión, como estas que analizamos aquí y otras similares, apenas se reconoce la actualidad de los conflictos sociales, que se limitan, y aun eso con una fuerza muy reducida, a patrones y obreros. Si no se reconoce la existencia de conflicto, es imposible que la imagen de las clases sociales sea antitética, e incluso es muy poco probable que se trate de una imagen de clases claramente separadas: más bien es un continuum en el que los sujetos se sitúan sólo en el "aquí y ahora», porque tienen plena consciencia de que la posición que ocupan es distinta de la que ocuparon sus 
padres (más del 60 por 100 dice tener mejores estudios, ingresos y nivel de vida, y más de la mitad dice tener un status laboral más alto). Y no sólo eso: confían en su propia capacidad de éxito y en la capacidad de otros individuos para seguir logrando cambios de ubicación en las posiciones sociales, que inevitablemente provocan la modificación de la estructura de clases percibida.

\section{III.d) Estabilidad y variación de las imágenes: lo que enseñan las series CIRES}

A pesar de las variaciones entre distintas fuentes, en el quinquenio 19901994 las autopercepciones de clase de los españoles parecen haber sido muy estables. Así se deduce de los treinta estudios CIRES realizados en ese período (tabla 6), que, además de mantenerse bastante estables, no muestran ninguna tendencia definida al crecimiento o decrecimiento de los cinco niveles de referencia (salvo el crecimiento de la clase media-baja, que es constante en las dos medias interanuales).

La utilidad mayor de los estudios CIRES para la investigación sociológica es su carácter periódico: esto permite no sólo una imagen estática de la distribución, sino también una saludable distancia respecto a los propios resultados que no es posible respecto a los datos de los estudios no periódicos. Como podemos comprobar en las variaciones intermensuales, hay diferencias entre los treinta estudios, aunque nunca se altere sensiblemente el sentido global (esto es, la forma) de la distribución. Si en lugar de contar con treinta estudios idénticos se hubieran de extraer conclusiones sobre uno cualquiera de ellos, tal como ocurre con las encuestas no periódicas, podrían presentarse cifras comprendidas en cualquier punto intermedio entre los valores mínimo y máximo obtenidos en las treinta encuestas. No podemos saber con exactitud en qué medida las variaciones se deben a cambios reales en la autopercepción, especialmente en los estratos que cambian erráticamente a lo largo de los cinco años. Las diferencias no son importantes en términos absolutos y la mayor distancia entre mínimo y máximo (once puntos) se produce en la clase mediabaja, que crece en las dos medias interanuales. Pero más que las diferencias absolutas importan las relativas: una diferencia de cinco puntos en la clase media-alta (entre 2 y 7) equivale a más que triplicarla, igual que una diferencia de seis puntos en la clase baja (entre 6 y 12) equivale a duplicarla.

La clase social subjetiva representa el polo más cualitativo de la desigualdad y, en cierto modo, el más rico y el que requiere mayor sutileza conceptual para su análisis. La disparidad entre la imagen "experta» y la autoimagen es un desafío a la capacidad de las herramientas intelectuales para medir y, sobre todo, entender la realidad social que estudian. Las encuestas CIRES ponen de relieve de modo sistemático que la clase social subjetiva correlaciona poco con los restantes indicadores de posición, especialmente con los indicadores sintéticos (como el de índice de status socioeconómico familiar) que no la incluyen en su base. Así, los ingresos familiares mensuales declarados tienen una correlación 


\section{TABLA 6}

La clase social subjetiva: variaciones interanuales e intermensuales en las encuestas CIRES 1990-1994

Alta ..................................

Media-alta ........

Media-media ..................

Media-baja

Baja ..........

NS/NC

\begin{tabular}{|c|c|}
\multicolumn{2}{|c}{19} \\
\hline Valor & \\
medio & M \\
\hline$*$ & \\
5 & \\
56 & \\
27 & \\
10 & \\
2 & \\
\hline
\end{tabular}

\begin{tabular}{c} 
1990-91 \\
Minimo \\
\hline 0 \\
3 \\
52 \\
23 \\
6 \\
1
\end{tabular}

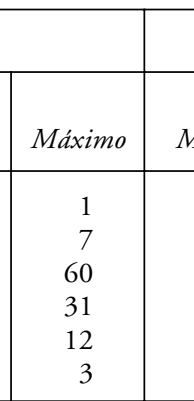

\begin{tabular}{c|c}
\multicolumn{2}{|c}{1992} \\
Medio & M \\
\hline$*$ & \\
3 & \\
57 & \\
29 & \\
8 & \\
2 & \\
\hline
\end{tabular}

\begin{tabular}{c|c}
\multicolumn{2}{|c|}{ 1992-93 } \\
\hline Minimo & M \\
$*$ & \\
2 & \\
54 & \\
27 & \\
6 & \\
1 &
\end{tabular}

\begin{tabular}{c|c} 
& \\
Máximo & N \\
$*$ & \\
5 & \\
58 & \\
32 & \\
10 & \\
3 &
\end{tabular}

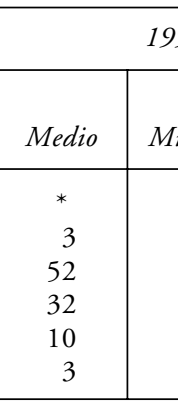

FUENTE: Elaboración de la autora sobre datos de:

CIRES, «La realidad social en España, 1990-91».

CIRES, «La realidad social en España, 1992-93».

CIRES, «La realidad social en España, 1993-94». 
líneal (R) con este indicador sintético del 0,76 (1993-94) y del 0,56 con la posición social o 0,52 con el nivel de estudios del entrevistado, pero la correlación es sólo del 0,34 con la clase social subjetiva. Y entre el índice de status socioeconómico familiar y la clase social subjetiva el coeficiente de correlación (1993-94) es sólo del 0,28.

Ante esta permanente y extendida disparidad, la investigación sociológica se enfrenta a un desafío teórico y metodológico. Puede concluirse («muerto el perro se acabó la rabia») que los entrevistados son incapaces de autoconocerse o de conocer la sociedad de la que forman parte, en cuyo caso gran parte de la investigación por encuesta u observación extensiva carecería de sentido. También, concluirse que la normatividad es más compulsiva en este tema que en otros temas próximos, pero salvo la persistente diferencia en los datos, que es lo que hay que explicar, no parece que esta interpretación cuente con una sólida base de apoyo. Y, finalmente, es posible suponer que la investigación sobre el «ser» de la sociedad se aleja del modo en que los ciudadanos la «sienten», y el remedio a este distanciamiento no es tanto dejar de escuchar las opiniones de los legos cuanto escucharlas mejor y más detenidamente.

\section{III.e) Torres, pirámides y estrellas: la nueva iconografía sociológica}

El International Social Survey Program de 1992 (CIS, estudio núm. 2046) presentó una novedad interesante respecto a otras encuestas españolas, que fue la utilización de tarjetas con la representación gráfica de varios tipos de distribución de la desigualdad (gráfico 1). El tipo 1 se denomina «sociedad polarizada de clases bajas»; el 2, "sociedad gradual de clases bajas»; el 3, "sociedad de clases medias-bajas»; el 4, «sociedad canónica de clases medias»; y el 5, «sociedad de clases medias-altas».

Los tipos 1 y 2 se han considerado por los entrevistados como los que mejor reflejan la sociedad española (23 y 37 por 100 , respectivamente, los seleccionaron) y los tipos 4 y 5 fueron los más citados como deseables ( 43 y 42 por 100 , respectivamente).

La operación de visualización de la estructura de clases no es sencilla; pero, además de la dificultad intrínseca de la comparación entre los entrevistados (esto es, qué quiere decir cada uno cuando se adhiere a uno u otro tipo de representación y de modelo), estas figuras geométricas entrañan muchas tomas de posición teóricas y metodológicas sobre las que vale la pena reflexionar tanto como sobre los resultados.

Las pirámides de las clases sociales son perfectamente simétricas respecto a su eje vertical. Pero ¿qué significado tiene este eje? Sin duda, se trata de una extensión de las pirámides de población que han popularizado los demógrafos (de lo contrario se representarían asimétricamente, a partir del punto cero), en las que varones y mujeres ocupan distintas secciones respecto al eje (derecha e 


\section{GRAFICO 1}

Las imágenes de la desigualdad en el ISSP, 1992

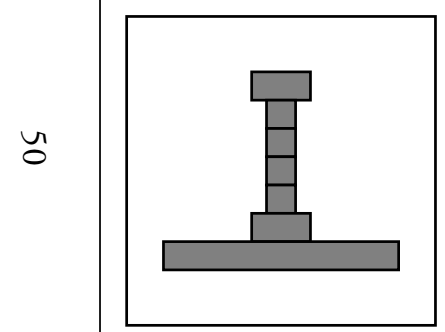

Tipo 1

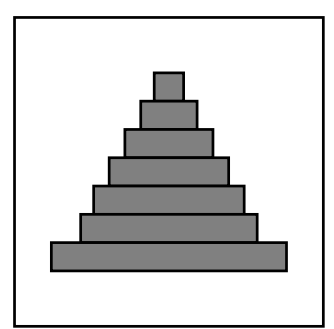

Tipo 2

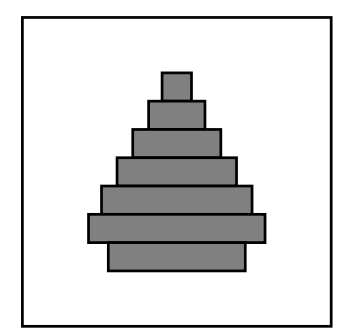

Tipo 3

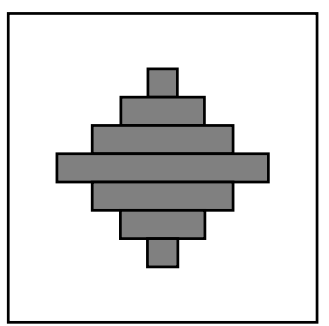

Tipo 4

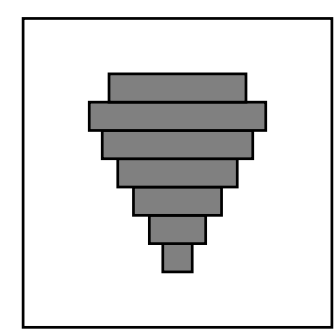

Tipo 5

Fuente: CIS, Las actitudes ante la desigualdad en España, Colección Opiniones y Actitudes. Informes, redacción de F. J. Moya y A. VAllejos, Madrid, 1995, p. 23 
izquierda). Sin embargo, en las pirámides de clases se solventa, olvidándolo, el sentido de este eje vertical.

En el ISSP todas las figuras son homogéneas en el número de estratos y ofrecen la misma distancia entre los límites inferior y superior; sin embargo, éste es precisamente un rasgo que diferencia de modo importante a las sociedades en función de su grado de desigualdad, y no sólo el número de posiciones de cada estrato. Por otra parte, la quinta figura es sólo comprensible si se refiere a una sociedad quimérica (todos o casi todos son de clase elevada) porque, por definición, en una escala relacional la abundancia de posiciones altas conlleva su conversión en medias; o, lo que es lo mismo, la modificación gráfica de la distribución. Esta figura puede representar una sociedad de «altas» solamente si no es una escala relacional (por ejemplo, si se refiere a una distribución real de la población sobre una escala de rentas previamente establecidas) o si es relacional respecto a otras pirámides dependientes (como sería, por ejemplo, la representación de la desigualdad en un paraíso fiscal al que sólo accediesen los ciudadanos más ricos de los países restantes). De hecho, en el mismo estudio se pregunta sobre cuánto «deberían ganar» y sobre "cuánto ganan» varias ocupaciones y las respuestas sólo otorgan un intervalo de 2,2 veces en el "debe ser» y de 6 en el «es»: lo que, si la representación gráfica se realizase teniendo en cuenta solamente estos datos, equivaldría a una escala de sólo 2,2 tramos para el modelo ideal y de 6 tramos para la representación real.

Una de las aportaciones metodológicas más interesantes del ISSP español, aunque sea como carencia, es la demostración de que gran parte de los entrevistados no responden a la solicitud de valoración de ingresos reales e ideales de las ocupaciones. Sólo en el caso de los «trabajadores cualificados en una fábrica" superaron los casos válidos a los no válidos, pero para los propietariosgerentes la proporción es de uno a cuatro, y para el conjunto hay doble cantidad de no respuesta que de respuesta. En la pregunta sobre las retribuciones ideales también son mayoría las respuestas no válidas. Ante estos datos es muy arriesgado presentar conclusiones. Puede suponerse que los que no responden ofrecerían una distribución similar a la de los que sí lo hacen, pero también es probable, e incluso más probable, que la falta de respuesta conlleve posiciones ideológicas que apartan a este grupo de los que responden. Noya y Vallejos, que analizan los resultados en el informe Las actitudes ante la desigualdad en España, se percatan de esta limitación, que debería ser objeto de mayor atención porque debilita extraordinariamente el alcance de otras conclusiones basadas en los mismos o similares datos.

La imagen de la sociedad española que se desprende del ISSP de 1992 contrasta fuertemente con la que se deriva de los autoposicionamientos o imágenes subjetivas de clase en otros muchos estudios: por ejemplo, la que refleja el gráfico 2, obtenida a partir de la Encuesta de Nuevas Demandas (1990). Si nos atuviésemos a la imagen de sí mismos que los ciudadanos proyectan (y la END no es la excepción sino la regla, porque en la mayoría de las encuestas es mayoritaria la pertenencia subjetiva a la clase media), tendríamos que introducir 
nuevas metáforas plásticas. La vieja iconografía de las clases, con sus formas piramidales, cede lugar a nuevas imágenes de torres y de husos. Y en el plano subjetivo, cuyo realismo a efectos vivenciales y políticos no es desdeñable, la metáfora que hoy predomina toma la forma de una estrella.

\section{GRAFICO 2}

Imagen externa y autoimagen de clase

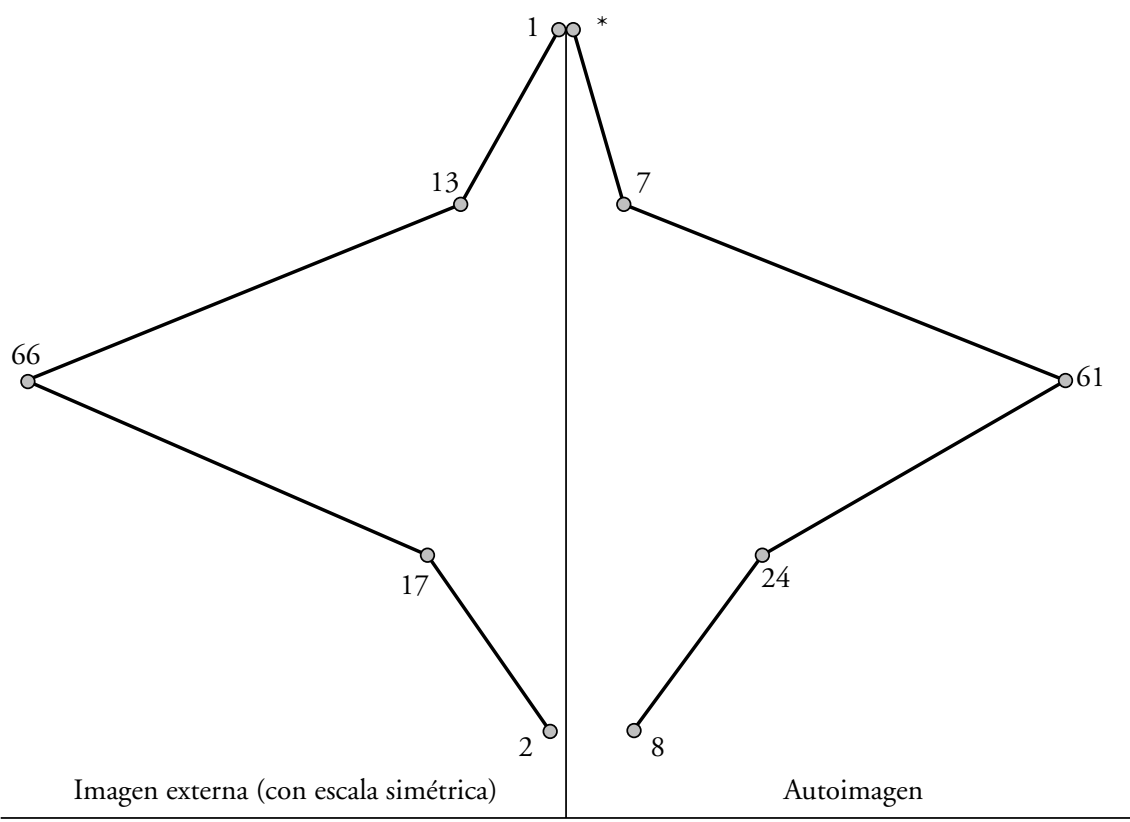

FuENTE: Encuesta de Nuevas Demandas, 1990. 


\section{REFERENCIAS}

AbBot, P., y SAPSFORD, R. (1987): Women and Social Class, Tavistock, London.

Argyle, M. (1994): The Psychology of Social Class, Routledge, London.

BANCO DE EsPaÑa (1996): Boletín Económico, julio-agosto.

BANDRÉS, E. (1990): Los efectos de los gastos sociales sobre la distribución de la renta de España, Instituto de Estudios Fiscales, Madrid.

Bosch, A.; Escribano, C., y SÁNCHeZ, I. (1989): Evolución de la desigualdad y la pobreza en España, Instituto Nacional de Estadística, Madrid.

CACHÓN, L. (1989): ¿Movilidad social o trayectoria de clase? Elementos para una crítica de la sociología de la movilidad social, Siglo XXI-CIS, Madrid.

CIRES (1990-1991): La realidad social en España.

- (1992-1993): La realidad social en España.

- (1993-1994): La realidad social en España.

- (Abril 1995): Informe sobre desigualdades sociales.

CIS (1995): Las actitudes ante la desigualdad en España. Resultados del estudio 2046, redacción de F. I. Moya y A. Vallejos, Madrid.

CoXon, A. P. M., y DAVIES, P. M. (1986): Images of Social Stratification, Sage, London.

Crompton, R., y Mann, M. (1986): Gender and Stratification, Polity Press, Cambridge.

Díaz-SAlaZAR, R. (1990): ¿Todavía la clase obrera?, Ediciones Hoac, Madrid.

DurÁn, M. A. (1983): Desigualdad social y enfermedad, Ed. Tecnos, Madrid.

- (1994): «Viejas y nuevas desigualdades: la dialéctica entre observadores y observados», Revista Internacional de Sociología, núms. 8-9, pp. 61-89.

- (1995): «Necesidades sociales y nivel de satisfacción en la década de los noventa», en P. Folguera (comp.), Otras visiones de España, Ed. Pablo Iglesias, Madrid, pp. 213-217.

ENGELS, F. (1972): El origen de la familia, la propiedad privada y el Estado, Ayuso, Madrid, p. 220 (1. a ed., 1984).

FOESSA (1983): Informe sociológico sobre la situación social en España, 1975-1983, Fundación Foessa, Euramérica, Madrid.

- (1994): Informe sociológico sobre la situación social en España, Fundación Foessa, Madrid.

FUNDACIÓN ARGENTARIA: Boletín Informativo del Programa de Estudios sobre Igualdad y Distribución de la Renta y la Riqueza:

- BeltrÁn, M. (1992): "Estratificación y clases sociales», diciembre.

- Bandrés, E., y Cuenca, A. (1995): «Aspectos redistributivos del sistema de pensiones en España», marzo.

- MAte, R. (1995): «Pensar la igualdad y la diferencia. Una reflexión filosófica», abril.

- Zamora, F. (1995): «Los movimientos de cambio de vivienda de la población española en el período 1981-1991», abril.

GonZÁleZ, J. J. (1992): Clases sociales: estudio comparativo de España y la Comunidad de Madrid, 1991, Comunidad de Madrid, Departamento de Estadística, Madrid.

II Simposio sobre Desigualdad y Distribución de la Renta (1995) (del 5 al 9 de junio, Madrid):

- Arango, J., y Gabarro, M.: Actitudes hacia la desigualdad: una perspectiva internacional.

- CaRABaña, J.: El proceso de logro de estatus con datos de la encuesta sociodemográfica.

- Noya, F. J.: Las actitudes ante la desigualdad en España: Igualitarismo y Justicia Distributiva en las encuestas de opinión.

JORNADAS DE ECONOMÍA LABORAL (1995) (del 7 al 9 de junio, Alcalá de Henares):

- LÁzaro, N.; Moltó, M. L., y SÁnchez, R.: Unemployment Determinants for Women in Spain, Departamento de Análisis Económico, Universidad de Valencia.

- Prieto Rodríguez, J.: Discriminación salarial de la mujer y permanencia laboral, Departamento de Economía, Universidad de Oviedo.

SÁnCHEZ, M. a I., y ARCAICO SuSO, A.: Aplicación de un modelo de ocupabilidad al mercado de trabajo en Alava. Los desempleados mayores de 45 años, Departamento de Economía Aplicada I, Universidad del País Vasco.

- Ullibarri, M.: Indices descomponibles de medición de la discriminación, Departamento de Economía, Universidad Pública de Navarra. 


\begin{abstract}
Rather than constituting a study of social inequalities as such, this paper sets out to study the theoretical and methodological implications of the instruments used to measure them and focuses on the more subjective manifestations of inequality: self-perception and social structure representation.

The paper is divided into three parts. Part One examines areas that affect the subjective definition of class, distinguishing between being, feeling and doing. Part Two presents, as systematically and briefly as possible, the results of almost 50 years (1950-1995) of empirical research into social classes conducted in Spain. This presentation looks at the different approaches taken by researchers and examines their effect on the results obtained. Part Three presents the hitherto unpublished —or as yet narrowly circulated - results of various national surveys recently conducted by CSIC and CIRES which consider the subject of social inequality and its attitudinal and autoperceptive manifestations. By drawing on these results and comparing them with those of the other studies, the author analyses the collective Spanish imaginarium in terms of social structure - what one might call the new sociological iconography — and the role played by social agents in shaping these images.
\end{abstract}

